\title{
An unusual cause of abdominal obstruction in a 10 -year-old boy successfully treated by endoscopy
}

Duodenal duplication cysts are congenital anomalies caused by embryonic malformations. They are extremely rare and account for only $4 \%$ of all gastrointestinal (GI) tract duplications. Symptoms mainly occur during the first decade of life [1].

We report here the case of a 10 -year-old boy who developed upper GI obstruction caused by a major acute bleed within a duodenal duplication cyst (> Fig. 1). He was initially treated with upper GI aspiration with a nasogastric tube.

After a multidisciplinary discussion, we decided to perform an endoscopic marsupialization of the cyst to treat the obstruction and assist with the forthcoming surgery ( $\vee$ Video 1 ). After the cyst had been located during an initial upper Gl endoscopy, an endoscopic ultrasound (EUS) was performed to clarify the situation. The cyst was found to be $7.4 \times 4.4 \mathrm{~cm}$ and had both solid and liquid components (> Fig. 2 ). It was punctured to confirm the recent bleeding and to enable a guidewire to be placed inside, thereby facilitating the rest of the procedure by making the entry point visible despite the recent bleeding. A colonoscope with a hood was then used to create a large incision on top of the cyst using a DualKnife (Olympus) and following the guidewire. After the inside of the cyst had been penetrated and the liquid component sucked out, a snare was used to remove the remaining clots. The mucosal layer was present only at the bottom of the cyst; only the typical muscular layer was present elsewhere ( $\triangleright$ Fig.3). Coagulation of small bleeding spots was performed with hot biopsy forceps and a double-pigtail stent was placed inside the cyst as there were remaining clots inside. The patient was able to eat the day following the procedure.

To our knowledge, this is one of the first case reports showing endoscopic mar-

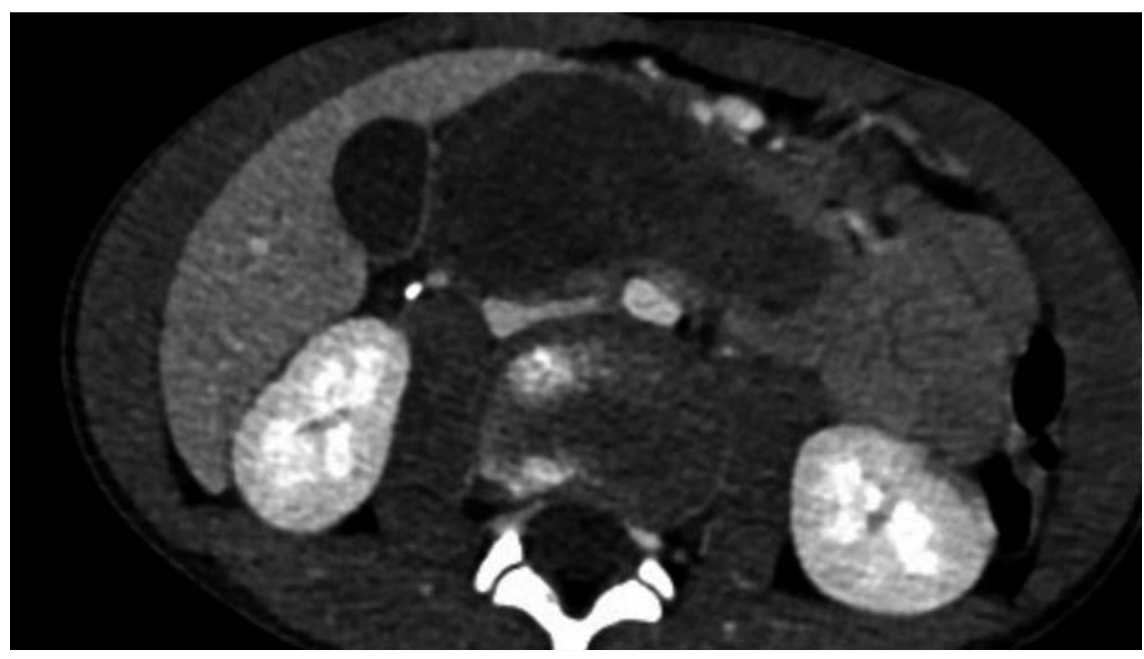

Fig. 1 Computed tomography image showing a duodenal duplication cyst in a 10-year-old boy.

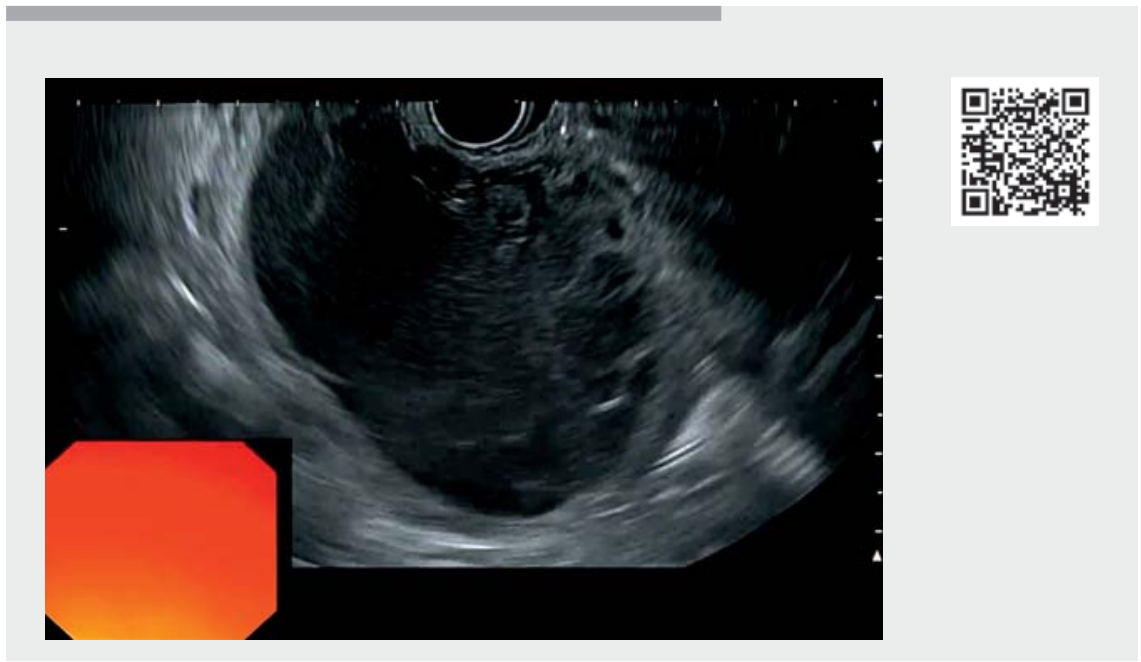

$\checkmark$ Video 1 An unusual cause of abdominal obstruction in a 10-year-old boy successfully treated by endoscopy.

supialization of a hematic duodenal duplication cyst [2]. This technique was effective and safe and allowed risky emergency surgery to be avoided.

Endoscopy_UCTN_Code_TTT_1AO_2AZ

\section{Competing interests}

The authors declare that they have no conflict of interest. 


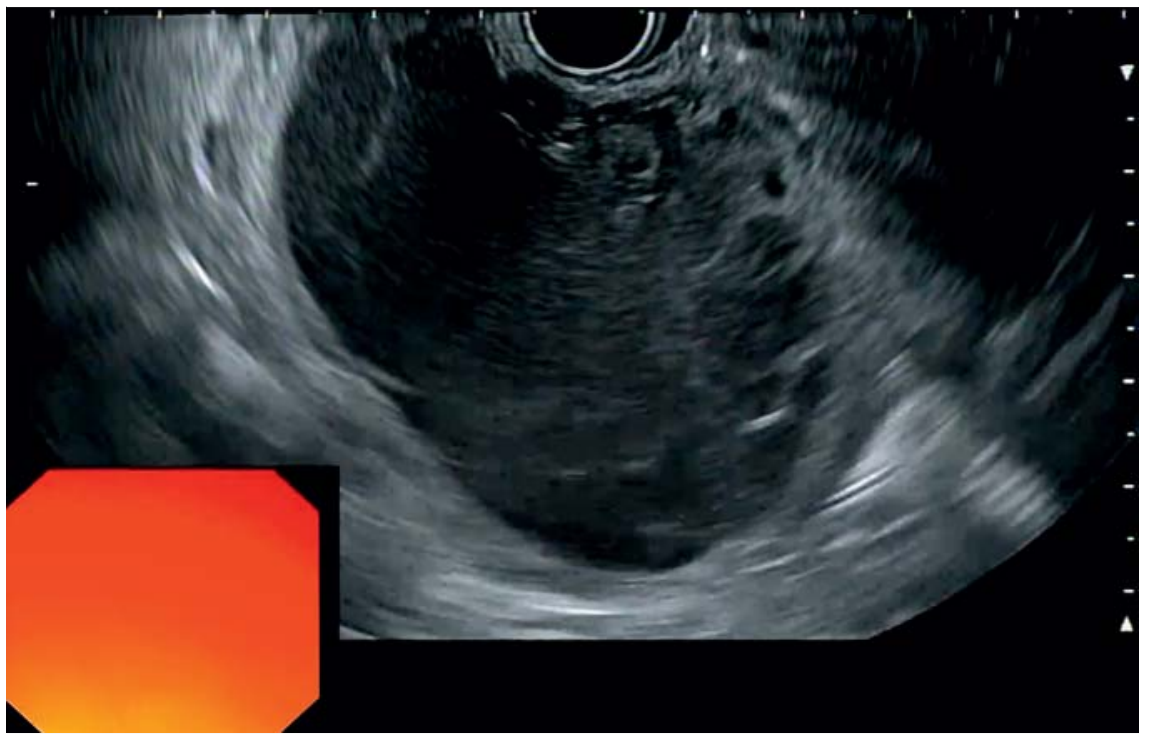

Fig. 2 Endoscopic ultrasound image of the duodenal duplication cyst.

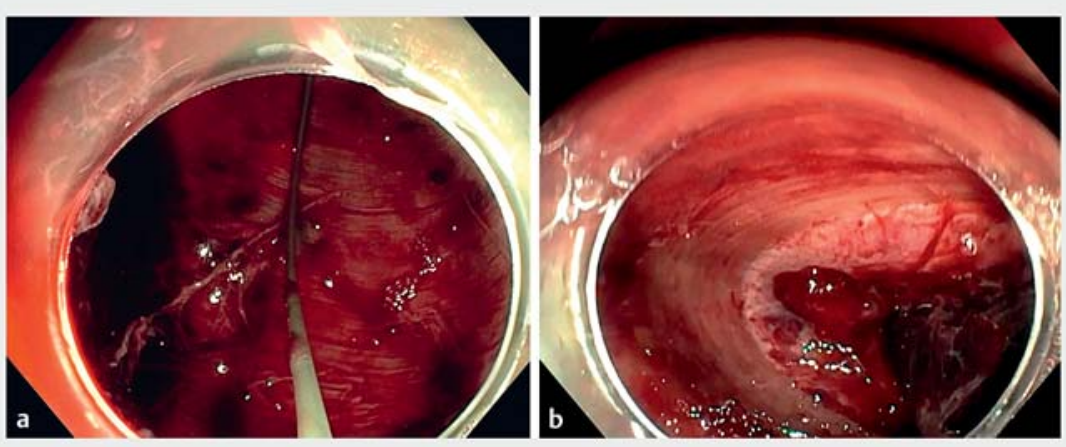

- Fig. 3 Endoscopic images showing: a a guidewire inside the duodenal duplication cyst, with the muscular layer visible behind; $\mathbf{b}$ the inside of the duodenal duplication cyst, with the muscular layer, mucosa, and remaining blood clots visible.

The authors

Lucile Héroin ${ }^{1}$, Pierre Lafeuille ${ }^{2} @$, Guillaume Rossignol ${ }^{3,4}$, Sophie Heissat ${ }^{5}$, Remi Dubois ${ }^{3}$, Jérôme Rivory ${ }^{2}$, Mathieu Pioche ${ }^{2}$

1 Gastroenterology and Hepatology Unit, Hôpitaux Universitaires de Strasbourg, Strasbourg, France

2 Department of Endoscopy and Hepatogastroenterology, Pavillon L, Edouard Herriot Hospital, Lyon, France
Corresponding author

\section{Lucile Héroin, MD}

Gastroenterology and Hepatology Unit, Hôpitaux Universitaires de Strasbourg, 1 quai Louis Pasteur, 67000 Strasbourg, France

lucileheroin@gmail.com

References

[1] Dipasquale V, Barraco P, Faraci S et al. Duodenal duplication cysts in children: clinical features and current treatment choices. Biomed Hub 2020; 5: 1-13

[2] Gjeorgjievski M, Manickam P, Ghaith G et al. Safety and efficacy of endoscopic therapy for nonmalignant duodenal duplication cysts. Medicine (Baltimore) 2016; 95: e3799

Bibliography

Endoscopy 2022; 54: E610-E611

DOI 10.1055/a-1722-2250

ISSN 0013-726X

published online 26.1.2022

(c) 2022. Thieme. All rights reserved.

Georg Thieme Verlag KG, Rüdigerstraße 14

70469 Stuttgart, Germany

\section{ENDOSCOPY E-VIDEOS}

https://eref.thieme.de/e-videos

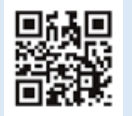

Endoscopy E-Videos is an open access online section, reporting on interesting cases and new techniques in gastroenterological endoscopy. All papers include a high quality video and all contributions are freely accessible online. Processing charges apply (currently EUR 375), discounts and wavers acc. to HINARI are available.

This section has its own submission website at

https://mc.manuscriptcentral.com/e-videos
5 Hépatologie gastroentérologie et nutrition pédiatrique, Hôpital Femme-Mère-Enfant Hospices Civils de Lyon, Bron, France 